\title{
EDITORIAL
}

\section{Publicações Científicas na Área Médica}

\author{
Scientific Publications in the Medical Field
}

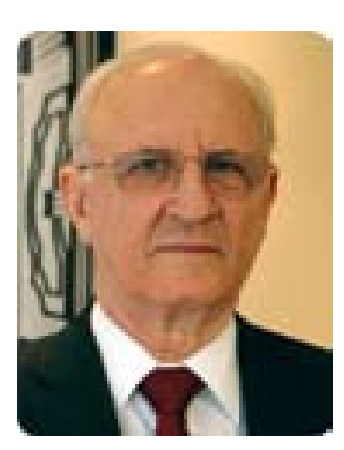

\author{
Gilson Soares Feitosa ${ }^{1}$ \\ ${ }^{1}$ Editor-Chefe da Revista Cientifica do Hospital Santa Izabel; ${ }^{2}$ Diretor Técnico Assistencial \\ do Hospital Santa Izabel; Salvador, Bahia, Brasil
}

Uma publicação médica refere-se a todas as formas possíveis de comunicação escrita ou, hoje em dia, por meio áudio-visual, em periódicos, livros, jornais e outras fontes de mídias.

Nos periódicos que se destinam à área de saúde, tais publicações se apresentam como artigos de revisão ou atualização, análise crítica, comentários sobre temas ou aos autores, respostas dos autores, editoriais e outras formas gerais de comunicação, ou como resultado de pesquisas que vão desde relato de casos, a observações sistematizadas, ensaios clínicos.

Os relatos de casos se referem à apresentação de características inusitadas de um caso clínico isolado. O British Medical Journal Case Report tolera até 3 casos com caraterísticas semelhantes e acima disso rotula como relato de série.

As observações sistematizadas se referem a estudos observacionais, longitudinais ou retrospectivos, relato de séries, estudos de coortes, revisões sistemáticas, metanálises e outras formas de observação.

E os ensaios clínicos testam hipóteses, geralmente de forma prospectiva e, preferencialmente, de forma aleatorizada.

Os periódicos mais relevantes são aqueles que contêm maior quantidade de publicações dessa última natureza, principalmente dos ensaios de pesquisa originais.

De qualquer forma, a ciência se imbrica com a comunicação. É obrigação inerente do cientista comunicar ao meio seus achados em prol do desenvolvimento e para benefício do ser humano.

Imagine-se um gênio pintor, esquizofrênico, que ao findar cada pintura, possivelmente maravilhosa, a destruísse. Para a humanidade ele seria

Correspondence addresses: Dr. Gilson Feitosa gilson-feitosa@uol.com.br

\section{Copyright}

(C) 2019 by Santa Casa de Misericórdia da Bahia. All rights reserved.

ISSN: 2526-5563 irrelevante. Dessa forma, a comunicação é indispensável na Ciência.

Há seis anos editoramos a Revista Científica do Hospital Santa Izabel - nos três primeiros anos denominada de Revista de Saúde do Hospital Santa Izabel - como um veículo de comunicação do que se processa em ciência médica e na área de saúde nesse nosocômio.

Dentro do escopo originalmente traçado, poderíamos dizer que foi um sucesso, levando-se em conta sua publicação trimestral ininterrupta e sem 
atrasos nesse período, atestando para aquilo em que acreditávamos que era a existência de uma massa crítica de profissionais de grande desenvolvimento em várias áreas do Hospital, capazes de fazer frente a esse desafio.

Agora estamos nos preparando para alçar voos mais distantes tornando a nossa revista de alcance nacional e internacional, indexando-a junto aos agentes regulatórios mais significativos de forma progressiva, e tornando-a acessível para publicação científica fora dos nossos liames.

Teremos uma atenção especial para as publicações originais que serão revistas por pares altamente qualificados e com publicação em língua inglesa para que alcancem o mundo.

Consolidamos, dessa forma, o cumprimento de uma das missões do Hospital Santa Izabel e da Santa Casa da Bahia, de contribuir para a educação médica e com total apoio da alta gestão da Instituição, que sempre se mostrou sensível a esses propósitos. 